\section{Estudo \\ CoDebate}

em Testão

Plamejamento
Revista Estudo \& Debate, Lajeado, v. 28, n. 3, 2021. ISSN 1983-036X

DOI: http://dx.doi.org/10.22410/issn.1983-036X.v28i3a2021.2820

\title{
COMPLIANCE NO ÂMBITO DO DIREITO PENAL: O PROCESSO DE MITIGAÇÁO E PREVENÇÁO DO CRIME DE LAVAGEM DE CAPITAIS NA SEARA EMPRESARIAL
}

\author{
Felipe Augusto Silva Custódio ${ }^{1}$, Marcela Dias Costa de Castro Silva²
}

\begin{abstract}
Resumo: $\mathrm{O}$ presente artigo tem por objetivo demonstrar a utilizaçáo dos programas de compliance ou programas de integridade como mecanismos de proteção em face do crime de lavagem de capitais no âmbito empresarial. Sabe-se, que os programas de compliance estáo relacionados ao estado de conformidade das organizaçóes e que, por meio de esforços institucionais, visam a, em regra, prevenir, detectar e responder a possíveis problemas de desvios entre as normas estabelecidas pelas organizaçōes e as condutas praticadas pelas pessoas físicas ou jurídicas. Nesse norte, sabe-se que a seara empresarial é um campo fértil para o cometimento de diversas condutas tidas como ilícitas pelo ordenamento jurídico brasileiro e, um exemplo de um ilícito é o crime de lavagem de capitais, que atualmente ganhou uma nova roupagem no âmbito empresarial, não tratando, somente, da utilização do tráfico de drogas para converter tais proveitos econômicos ilícitos, com uma aparência lícita no mercado empresarial/financeiro. Assim, discutem-se a utilizaçáo dos programas de compliance no interior das instituiçóes empresariais, como uma ferramenta de prevençâo e correçâo a possíveis ilícitos originados do crime de lavagem de capitais cometidos pela pessoa jurídica e/ou pessoa física/prepostos integrantes da organização empresarial. Nesse norte, utiliza-se como metodologia o método jurídico teórico, com o exame de legislaçōes, de doutrinas penais e empresariais existentes sobre o tema, bem como a análise de dados decorrentes de pesquisas indiretas sobre os programas de compliance no ámbito empresarial e penal.
\end{abstract}

Palavras-chave: Programas de compliance. Direito Penal. Empresas. Empresários. Ética Empresarial. Corrupção.

1 Mestre em Direito pela Faculdade de Direito Milton Campos. Pós-graduado em Direito Penal e Processo Penal pela Universidade Candido Mendes/RJ. Pós-graduado Direito Tributário pela PUC/MG. Pósgraduado em Direito do Trabalho e Processo do Trabalho pelo Centro Universitário UNA de Sete Lagoas. Graduado em Direito pelo Centro Universitário de Sete Lagoas/UNIFEMM. Professor de Direito do Trabalho, Processo do Trabalho e Direito Empresarial do Centro Universitário de Sete Lagoas/UNIFEMM. Advogado.

2 Mestra em Direito Empresarial pela Faculdade de Direito Milton Campos. Pós-graduada em Direito Tributário pela Pontifícia Universidade Católica de São Paulo. Graduada em Direito pela FUMEC/MG. Advogada. 


\title{
COMPLIANCE UNDER CRIMINAL LAW: THE PROCESS OF MITIGATION AND PREVENTION OF THE CRIME OF CAPITAL LAUNDERING IN SEARA EMPRESARIAL
}

\begin{abstract}
This article aims to demonstrate the use of compliance programs or integrity programs as protection mechanisms in the face of the crime of money laundering in the business environment. It is known that compliance programs are related to the state of compliance of organizations and that, through institutional efforts, they aim to, as a rule, prevent, detect and respond to possible problems of deviations between the standards established by organizations and organizations. conducts practiced by individuals or legal entities. In this north, it is known that the business field is a fertile field for the committing of several conducts considered illegal by the Brazilian legal system and, an example of an illegal one is the crime of money laundering, which currently has a new guise within business, not only dealing with the use of drug trafficking to convert such illicit economic gains, with a lawful appearance in the business / financial market. Thus, the use of compliance programs within business institutions is discussed as a tool for the prevention and correction of possible illicit acts originating from the crime of money laundering committed by legal entities and / or individuals / representatives of the business organization. In this north, the theoretical legal method is used as a methodology, with the examination of existing legislation, criminal and business doctrines on the subject, as well as the analysis of data resulting from indirect research on compliance programs in the business and criminal spheres.
\end{abstract}

Keywords: Compliance programs. Criminal Law. Companies. Businessmen. Business ethics. Corruption.

\section{INTRODUÇÁO}

Os programas de compliance visam, em síntese, a prevenir, detectar e a responder possíveis problemas de desvios entre as normas estabelecidas pelas organizaçóes e as condutas praticadas pelas pessoas físicas ou jurídicas, tendo como um de seus objetivos o combate aos atos de corrupção. Assim, o compliance atua com base nas premissas estabelecidas pela empresa, utilizando-se dos códigos de conduta ética, controles internos, e normas/ legislações externas em vigor.

Nesse norte, tem-se diversos atos/condutas ilícitas cometidas pelas pessoas jurídicas e, pessoas físicas/prepostos no âmbito empresarial, conforme é tratado pela Lei Anticorrupção brasileira (lei $\mathrm{n}^{\circ} 12.846 / 13$ ) e, um exemplo destes ilícitos é o crime de lavagem de capitais. Assim, em face das disposiçóes trazidas pelos programas de compliance, tal ferramenta pode ser produtiva ao prevenir e/ou corrigir tais ilícitos antes as suas características de controle.

Hoje o compliance é um dos meios legais para que as empresas e aqueles que estão presentes em seu vínculo corporativo ajam em sintonia com regulamentaçóes, normas, controles internos e externos presentes nas instituições ou em legislações vigentes. Nesse sentido, a hipótese que pretende responder ao tema-problema em que foi fixado o recorte epistemológico do presente trabalho é: i) os programas de compliance adequam-se na seara empresarial, como forma de prevenir o cometimento de ilícitos financeiros, como o crime de lavagem de capitais.

Nesse norte, utiliza-se como metodologia o método jurídico teórico, com o exame da legislação, das doutrinas penais e empresariais existentes sobre o tema, bem como a análise de dados decorrentes de pesquisa indireta sobre os programas de compliance e o crime de lavagem de capitais. 


\section{COMPLIANCE NO ÂMBITO DO DIREITO PENAL}

O termo compliance é é derivado da língua inglesa ${ }^{4}$. É um substantivo originado do verbo to comply with ${ }^{5}$, que significa "agir de acordo com", isto é, agir de acordo com uma determinada lei, como é o caso da Lei Anticorrupção brasileira, como também de acordo com uma norma institucional, um regulamento empresarial ou políticas internas.

Alexandre Alkmim Teixeira explica sobre o tema compliance:

O termo compliance tem sido largamente utilizado no mundo corporativo para se referir à conduta da empresa que se porta conforme as normas e àquilo que é esperado pela sociedade com relaçáo à sua postura negocial e social. Trata-se, pois, de um termo cuja amplitude permite desdobramentos nas mais diversas áreas: negocial, trabalhista, ambiental, concorrencial, tributária, dentre outras. Assim, compliance vai além do mero cumprimento da lei. A empresa que possui compliance busca demonstrar náo apenas a sua regularidade legal, mas, também, o seu comprometimento em atender às expectativas morais da sociedade em que ela está inserida. (TEIXEIRA, 2019, p. 31).

O compliance, em sua acepção principal, utiliza o termo "observância", que está diretamente vinculado ao cumprimento de normas, regimentos internos e externos, códigos de condutas éticas, convençóes e tratados internacionais, além de leis que dispóem sobre determinados atos ilícitos, com o intuito de coibir condutas futuras inadequadas.

Baseado na observância, o compliance ${ }^{7}$ está ligado a um estado de conformidade com as normas internas e externas que, por meio de esforços sistemáticos, visam basicamente a prevenir, a detectar e a responder a possíveis problemas de desvios entre as normas estabelecidas e a condutas praticadas pelas pessoas ou empresas, construindo, assim, uma cultura empresarial ética. Dessarte, o compliance atua na cultura da empresa como base

3 O termo Compliance é traduzido do inglês como conformidade, observância, complacência ou submissão, substantivo que advém do verbo inglês to comply cuja traduçáo é adequar, cumprir, obedecer. (CUNHA; SOUZA, 2017, p. 76).

4 Compliance vem da terminologia inglesa comply, que tem como significado não literal: "ato ou procedimento para assegurar o cumprimento das normas reguladoras de determinado setor". (DALLANORA, 2019, p. 64).

5 Compliance with the law is important for companies. Dicionário Linguee de inglês - português. Disponível em:<https://www.linguee.com.br/portugues-ingles/search?source=ingles\&query=Compliance $>$. Acesso em: 01 out. 2020.

6 Pode-se caracterizar, com isso, o compliance como um instituto de resiliência da instituição, transformador de falhas detectadas em oportunidades para demonstrar firmeza e integridade, bem como para aprimoramento dos procedimentos internos de controle. (COIMBRA; MANZI, 2010, p. 9).

7 Compliance pode ser definido entâo como conjunto de açôes e planos adotados facultativamente por pessoas jurídicas visando a garantir que cumpram todas as exigências legais e regulamentares do setor ou segmento econômico em que atuam, inclusive preceitos éticos e de boa governança administrativa, visando a evitar e punir adequadamente fraudes e atos de corrupção em geral. (CUNHA; SOUZA, 2017, p. 76). 
da governança corporativa, sendo um forte mecanismo na prevenção e no combate à corrupção ${ }^{8}$.

Luis Roberto Antonik (2016, p. 50) destaca que o compliance é um conjunto normativo que assegura o cumprimento de regras de determinado setor. $\mathrm{O}$ significado tem como objetivo identificar possibilidades de infraçóes, falta de cumprimento de uma norma legal ou atividades que se configurem como atos de corrupção.

O compliance hoje é um dos meios legais para que as empresas e aqueles que estão presentes em seu vínculo corporativo, ajam em sintonia com regulamentaçóes, normas, controles internos e externos presentes nas instituiçóes ou em legislaçóes vigentes. A utilização do compliance no crime de lavagem de capitais, conhecido, também, como "crime do colarinho branco", dificulta a realização do cometimento deste crime, pois tal o crime está relacionado a indivíduos, que em sua maioria estão ligados a grandes negócios?

Assim, o compliance baseia ${ }^{10}$ sua atuação em leis vigentes, códigos de condutas éticas e nas políticas especialmente desenvolvidas pelas organizações, para disseminação de princípios éticos e de responsabilidade social, tanto no setor público quanto no privado.

Gustavo Badaró e Pierpaolo Bottini (2016, p. 52) destacam que o escopo das políticas de compliance é o de garantir, sob uma perspectiva ex ante, o cumprimento das normas direcionadas à área de atuação de determinada instituição, a fim de evitar problemas jurídicos e de imagem decorrentes de falhas de organização interna que coloquem a empresa em situação de conflito com os atos regulatórios.

8 "A palavra corrupção deriva do latim corruptus que, numa primeira acepção, tem como significado "quebrado em peças", mas pode também significar apodrecido ou pútrido. Pode-se dizer, pois, que se trata de expressáo polissêmica, já que engloba significados diversos, tanto de natureza pública como privada. Junto a comportamentos de cunho sexual se somam outros, de caráter ético, comercial ou funcional. Assim, corrupção não é conceito juridico em si, mas um objeto que varia de acordo com o enfoque que lhe é dado pelo observador que sobre ela se detém". (JAPIASSÚ, 2007, p. 36).

9 É o delito que exige sujeito ativo qualificado, detentor de particular condição. Tal especialidade pode advir de circunstância fática ou de lei. Ilustrando, para cometer o crime de perigo de contágio venéreo (art. 130, $\mathrm{CP}$ ), demanda-se que o sujeito ativo esteja enfermo (qualidade de fato). Para praticar peculato (art. 312, $\mathrm{CP}$ ), exige-se que o sujeito ativo seja funcionário público (qualidade jurídica). (NUCCI, 2013, p. 79).

10 Um programa de compliance bem estruturado, no entanto, deve levar em consideração não apenas as obrigações legais, mas acompanhar os atos normativos expedidos pelos diversos órgãos que possam impactar no setor no qual as atividades são exercidas. (BADARÓ; BOTTINI, 2016, p. 59). 
Nesse passo, além da conceituação exposta do termo compliance, que está intimamente ligado ao aspecto ético das empresas, pode-se determinar que tal ferramenta está ligada aos seguintes aspectos ${ }^{11}$ : i) comportamento; ii) cumprimento; iii) observância; iv) regulação.

\section{ASPECTOS HISTÓRICOS E O CONCEITO DE LAVAGEM DE CAPITAIS}

Existem diferentes entendimentos com relação a data de início da antiga expressão "lavagem de dinheiro", conhecida nos tempos atuais como "lavagem de capitais". Alguns doutrinadores como Marcelo Batlouni Mendroni (2001), destacam que a atividade ilícita teve início na Inglaterra, através das condutas ilícitas que aconteciam dentro dos navios, como nas negociaçóes de armamentos, muniçóes por moedas mais caras, e em diversos outros negócios ilícitos, que aparentemente eram ou se tornavam lícitos.

De outro modo, a grande parte e maciça da doutrina destaca que a expressão surgiu entre os anos de 1920 e 1930 com a máfia norte-americana, os quais os criminosos daquela época utilizavam de lavanderias de roupas para acobertar o tráfico de drogas, jogos de azar, roubos, dentre outras condutas ilícitas, ficando, assim, fácil de movimentar uma grande quantia de dinheiro. Tais situaçôes são confirmadas na doutrina de Peter Lilley (2001, p. 37-38), que explica que à época tornava-se fácil justificar os valores obtidos pelas condutas ilícitas, pois toda a comunidade utilizava os serviços das lavanderias, que eram de propriedade dos criminosos.

Nesse sentido, Gustavo Henrique Badaró e Pierpaolo Cruz Bottini (2016, p. 29) destacam que o termo lavagem de dinheiro foi empregado inicialmente pelas autoridades norte-americanas para descrever um dos métodos utilizados pela máfia nos anos 30 do século XX para justificar a origem de recursos ilícitos.

Dessa mesma forma, Peter Lilley (2001, p. 39) destaca que era impossível determinar a quantidade de dinheiro que os criminosos movimentavam com as lavanderias, visto que a circulação vultuosa de dinheiro com estes serviços, tendo em vista da necessidade dos serviços para a população.

Nos dias atuais e de forma histórica, a lavagem de dinheiro ${ }^{12}$ não respeita ou respeitou qualquer fronteira ou qualquer tipo de programa governamental, visto que a lavagem de

11 Os pressupostos dados à noção de compliance podem, por vezes, parecer comezinhos. Mas não o são, ainda mais quando da verificação de sua interação com o Direito Penal. Sua estrutura é bastante interessante, mas causa uma certa preocupação quando vista sob prisma penal. É de se ver, de toda a forma, que a técnica dos programas de compliance não se mostra apenas como ornamentação de estilo das teorias do consenso - e nem mesmo da arbitragem ou dos sistemas de auditoria interna. Ela vai além: mostra-se como uma aceitaçáo institucionalizada, que combina as variadas possibilidades de comportamento decisório no âmbito empresarial. Orienta-se, em verdade, pela finalidade preventiva, por meio da programaçáo de uma série de condutas (condução de cumprimento) que estimulam a diminuição dos riscos da atividade. Sua estrutura é pensada para incrementar a capacidade comunicativa da pena nas relações econômicas, ao combinar estratégia de defesa da concorrência leal e justa com as estratégias de prevenção de perigos futuros. (SILVEIRA; DINIZ, 2015, p. 255).

12 A lavagem de dinheiro é o ato ou sequência de atos praticados para mascarar a natureza, origem, localização, disposição, movimentação ou propriedade de bens, com o escopo último de reinseri-los na economia forma com a aparência lícita. (BADARÓ; BOTTINI, 2016, p. 29). 
dinheiro aperfeiçoou-se no decorrer dos anos, passando da utilização e ganho em dinheiro em espécie, para qualquer tipo de bens/patrimônio em geral, conferindo uma aparência de licitude a bens ou valores pecuniários adquiridos de maneira ilícita.

Deste modo, a dinâmica ou a ideia da lavagem de dinheiro ou de capitais, possui como finalidade transformar o dinheiro ou o bem de determinada pessoa (física ou jurídica) que é ilícito ou sujo, com uma aparência lícita.

\subsection{A Lavagem de capitais e as organizaçóes criminosas}

Como destacado anteriormente, a lavagem de capitais é o processo de ocultação ou de simulação de bens, direitos ou valores, provenientes de uma infração penal, crime ou contravenção penal, com o objetivo de trazer a aparência lícita a esses recursos que foram adquiridos com essas condutas ilícitas, ou seja, transformar algo ilícito em visivelmente lícito.

Marcelo Batlouni Mendroni que destaca que a lavagem de capitais acontece independente de qualquer organizaçáo criminosa, ou seja, não depende da estrutura da organização criminosa para acontecer, pois a prática de lavar dinheiro ou capitais não depende necessariamente de quatro ou mais pessoas para se concretizar, conforme dispóe a Lei $n^{\circ} 12.850 / 2013$. Assim, faz-se importante diferenciar o versa a Lei no 12.850/2013, em seu $\$ 1^{\circ}$, do que ora está exposto no artigo 288 do Código Penal brasileiro.

A organização criminosa pressupóe a associação de quatro ou mais pessoas, de forma organizada, nos moldes da lei supracitada, com o objetivo de obter lucro, diferentemente da associação criminosa, que o quantitativo de pessoas é de três ou mais, com o fim de cometer crime, não especificando qual crime será cometido.

Assim, de acordo com a Lei no $12.850 / 2013$, para que se tenha uma organização criminosa, necessariamente deve ter quatro ou mais pessoas, mas para que haja o crime de lavagem de capitais, o mesmo pode ser feito por apenas um indivíduo, visto que não são todas as pessoas que lavam capitais, necessariamente fazem parte de uma organização criminosa.

\subsection{Características e fases da lavagem de capitais}

Gustavo Henrique Badaró e Pierpaolo Cruz Bottini (2016, p. 31) explicam que o processo de lavagem de dinheiro tem como antecedente necessário a prática de uma infração penal, momento de origem do recurso ilícito, e se inicia com a ocultação dos valores auferidos.

Assim, necessariamente o crime de lavagem de capitais pressupóe de forma taxativa uma ação, uma infração produtora, capaz de gerar bens, direitos e valores passíveis de ocultação e dissimulação. 
Ante a doutrina dominante e ao próprio Conselho de Controle de Atividades Financeiras (COAF), tem-se três fases da lavagem de capitais, o qual a primeira é a colocação (placement ${ }^{13}$ ), a segunda o mascaramento (layering) e, a terceira e a integraçáo (integration).

Quanto a colocaçấo, tem-se como norte pegar o dinheiro, valores ou direitos que são ilícitos e colocá-los no mercado, o qual necessariamente será movimentado. Já, a segunda fase que é a "mascaramento" ou "dissimulação", consiste em fazer uma série de movimentaçóes, para que não sejam percebidos o ponto inicial do dinheiro, o qual o condutor conseguirá afastar da origem, evitando possíveis rastreamentos.

A terceira e última fase é a integração, que nada mais é que integrar o dinheiro ou os capitais, já com o aspecto de licitude no mercado formal.

Nesse aspecto, Gustavo Henrique Badaró e Pierpaolo Cruz Bottini explicam:

\begin{abstract}
Assim, o processo completo de lavagem de dinheiro é composto por ao menos três fases: a ocultação, dissimulação e integração dos bens à economia formal. Nem sempre os contornos de cada uma dessas fases podem ser reconhecidos de forma precisa. Na prática, é comum a sobreposição entre as etapas do delito, sendo difícil identificar o término de uma e o início de outra. Ainda assim, é importante perceber a lavagem como um processo dinâmico que tem por objetivo final a integração do capital à economia lícita. Não se trata de um simples ato de ocultação, de um mero esconder bens de origem delitiva, mas de uma atividade voltada à simulaçáa, à confecção de uma roupagem legítima a recursos escusos, ainda que tal objetivo não seja necessariamente alcançado. (BADARÓ; BOTTINI, 2016, p. 32).
\end{abstract}

Importante destacar que segundo o Supremo Tribunal Federal, conforme julgamento do RHC-80816 ${ }^{14}$, para que haja a consumação da lavagem de capitais (êxito definitivo da ocultação), não se faz necessário a ocorrência e/ou êxito das três fases supracitadas, ou das quatro fases destacadas por alguns autores, a exemplo do Fausto de Sanctis que destaca sobre a existência da fase da reciclagem, mas o êxito em apenas uma fase já caracteriza tal ilícito penal.

\title{
4 O BEM JURÍDICO TUTELADO NO CRIME DE LAVAGEM DE CAPITAIS E A UTILIZAÇÁO DO COMPLIANCE COMO PREVENÇÃO E CORREÇÃO AOS ILÍCITOS PENAIS
}

Fernando Capez (2012, p. 31) entende que o bem jurídico tutelado pela norma é, portanto, o interesse de terceiros, pois seria inconcebível provocar a interveniência criminal repressiva contra alguém que está fazendo apenas mal a si mesmo.

Com o mesmo entendimento, Guilherme de Souza Nucci (2013, p. 19) explica que o bem jurídico cuida-se do interesse protegido pela norma jurídica; no campo penal,

13 Tendo em vista que os primeiros estudos e casos concretos sobre a lavagem de capitais foram feitas nos Estados Unidos, o Brasil herdou toda a doutrina norte-americana. Por isso que diversas expressóes do tema no direito brasileiro estão em Inglês.

14 Disponível em: $<$ http://redir.stf.jus.br/paginadorpub/paginador.jsp?docTP=AC\&docID=102742>. Acesso em: 01 out. 2020. 
conforme o tipo incriminador, pode-se identificar o bem tutelado, como vida, patrimônio, honra, dentre outros.

Nesse norte, o bem jurídico ${ }^{15}$ tutelado na lavagem de capitais dispóe de acordo com a doutrina de cinco correntes. A primeira corrente (minoritária na doutrina) defende que bem jurídico é o mesmo bem que a infração penal antecedente, ou seja, se o crime de lavagem de capitais advém do tráfico de drogas, o bem jurídico a ser tutelado nesse caso seria a saúde pública.

Marcelo Mendroni (2018, p. 69) explica que a segunda corrente trata que o bem jurídico tutelado nos crimes de lavagem de capitais seria a administração da justiça, ou seja, aqueles indivíduos que cometem tais crimes, estariam violando a administração da justiça.

Inerente a segunda corrente, Sergio Fernando Moro explica:

A terceira corrente seria a ordem econômico financeira ${ }^{16}$, visto que a mesma versa que se algum bem, dinheiro o valor que foi inserido de maneira ilícita proveniente da lavagem de capitais, a dita conduta estaria ferindo a livre concorrência, a livre iniciativa de mercado, gerando com tal prática um desequilíbrio no mercado. Tal corrente é a majoritária e, adotada pela maioria dos tribunais brasileiros. (MORO, 2010, p. 10-11).

Sergio Moro (2010, p. 11) explica que a quarta corrente trata da pluralidade de bens jurídicos, visto que para essa corrente, tudo é bem jurídico tutelado, com a saúde pública, a administração da justiça, sistema financeiro nacional, dentre outros. Imperioso destacar que a quarta corrente também é minoritária, não causando grande repercussão nos tribunais.

A quinta corrente trazida pelo doutrinador Fausto Martin De Sanctis (2010, p. 2829), trata da ordem econômico financeira de uma forma imediata, e a administração da justiça de uma forma mediata, pois o crime de lavagem de capitais pode lesar tanto a ordem econômico financeira e a administração da justiça.

Nesse sentido, destaca Marco Antônio de Barros:

O bem juridicamente protegido pela Lei de 'Lavagem' pode não ser exclusivamente de natureza socioeconômica, pois, na medida em que o crime antecedente produza apenas reduzida lesividade ao sistema econômico-financeiro, como sucede em órbita individual que escapa desse gênero difuso (ex.: extorsão mediante seqüestro), a proteção será de menor expressão, podendo até confundir-se com o justo interesse do indivíduo de obter ressarcimento pelos danos sofridos. Logo, náo se pode afirmar que o diploma

15 É o bem escolhido pelo ordenamento jurídico para ser tutelado e amparado. Quando se constituir em bem jurídico deveras relevante, passa ao âmbito de proteçáo penal, permitindo a formação de tipos incriminadores, coibindo as condutas potencialmente lesivas ao referido bem jurídico penal. (NUCCI, 2016, p. 59).

16 Um segundo objetivo, associado à criminalização da lavagem de dinheiro e à nova política criminal, consiste em coibir a influência disruptiva do crime no domínio econômico e político. Em um mundo extremamente competitivo, qualquer vantagem injusta na atividade econômica ou política pode guindar o beneficiado a uma posição de predominância, em prejuízo de seus concorrentes. No domínio econômico, isso pode significar um mercado dominado por criminosos, pois o empresário criminoso pode valer-se de recursos que não estâo disponíveis ao empresário honesto. (MORO, 2009, p. 10-11). 
penal em estudo se limita a reprimir exclusivamente açóes criminosas compatíveis com a macro-criminalidade na atividade criminosa destinada a reciclar capitais ilícitos, como frequentemente ocorre em relação aos crimes praticados contra a Administraçáo Pública. (BARROS, 2004, p. 99).

Dessa forma e, mesmo tendo diversas correntes que tratam sobre o bem jurídico tutelado na lavagem de capitais no território brasileiro, a doutrina convencionou que o bem jurídico tutelado é a ordem econômico financeira.

Relacionando o bem jurídico disposto pela terceira corrente que é a mais utilizada pelos tribunais pátrios, o programa de compliance no âmbito empresarial atuaria de forma relevante e consistente na prevenção e na correção de possíveis ilícitos penais causados pela pessoa jurídica, conforme disposto pela Lei no 12.846/2013, designada como "Lei Anticorrupção brasileira", como também pelos empregados/prepostos e, por aqueles que possuem qualquer tipo de relação empresarial com a instituição.

Luciano Santos Lopes e Renato Dilly Campos, explicam a importância dos programas de compliance, na delimitação da responsabilidade de empregados e prepostos ${ }^{17}$ em eventuais ilícitos:

\begin{abstract}
Primeiramente, o Compliance deve delimitar com precisão as tarefas pertinentes à cada preposto da empresa, bem como deve delimitar o funcionário responsável por sua fiscalização. Destarte, a instauração do Compliance Criminal é um mecanismo eficaz (mas não absoluto) de delimitação da responsabilidade de cada preposto pela delegação de funçóes. Ainda, o Compliance eficaz deve identificar os agentes responsáveis pela fiscalizaçáo da conduta que produziu o resultado antijurídico. Deste modo, a instauraçáo do Compliance Criminal auxilia a identificação dos agentes responsáveis pela conduta antijurídica, isentando (por muitas vezes) os demais envolvidos na cadeia executiva (geralmente, em razão de erro de tipo) da responsabilidade criminal que, sem o sistema, poderia lhes ser aplicada. (LOPES; CAMPOS, 2017, p. 27).
\end{abstract}

José Anacleto Abduch Santos (2015, p. 234) dispóe que a existência de mecanismos de "compliance" voltados a evitar ou reprimir atos lesivos à Administraçáo Pública demonstra a diligência e o cumprimento do dever de cuidado inerentes à prudência no trato dos negócios e atividades empresariais.

O Decreto no 8.420/2015, que regulamentou a Lei Anticorrupção, definiu em seu artigo 41, o que são os programas de integridade ou compliance:

Art. 41. Para fins do disposto neste Decreto, programa de integridade consiste, no âmbito de uma pessoa jurídica, no conjunto de mecanismos e procedimentos internos de integridade, auditoria e incentivo à denúncia de irregularidades e na aplicação efetiva de códigos de ética e de conduta, políticas e diretrizes com objetivo de detectar e sanar desvios, fraudes, irregularidades e atos ilícitos praticados contra a administração pública, nacional ou estrangeira. (BRASIL, 2015).

17 Designa a pessoa ou o empregado que, além de ser um emprestador de serviços, está investido no poder de representação de seu chefe ou patrão, praticando os atos concernentes a avença sob direção e autoridade do preponente ou empregador. Nesta razão, ao preposto atribui-se poderes de representação para praticar atos ou efetivar negócios que lhe são cometidos como funçóes e encargos permanentes. (SILVA, 2013, p. 1086). 
Diante da conceituação dada pela lei, verifica-se que os programas de compliance objetivam, em regra, versar e tratar: i) da prevenção aos atos de corrupção por meio de normas internas, externas e regramentos metodológicos diversos; ii) dos atos de corrupção e crimes a este análogos; iii) da imposição de uma cultura ética nas instituiçóes públicas e privadas; iv) da imposição de condutas éticas em todos os setores das empresas.

\section{CONCLUSÃO}

O principal objetivo deste artigo consistia em investigar a utilização dos programas de compliance no âmbito das empresas, como forma de prevenir e corrigir o crime de lavagem de capitais ocorridos nas operaçóes destas organizaçóes. Assim, discutiu-se o poder de controle dos programas de compliance na seara empresarial e penal.

Sabe-se que os programas de compliance estão relacionados ao estado de conformidade das organizaçôes. Em regra, visam, por meio de esforços institucionais, à prevenção, à detecção e à resoluçáo de possíveis problemas de desvios de condutas diante das normas estabelecidas pelas organizaçóes, que se pautam em regulamentos legais (como a "Lei Anticorrupção) ou autorregulatórios (como as normas do IBGC, da AMBIMA e da B3).

A lavagem de capitais nos tempos atuais e de forma histórica não respeita qualquer tipo de fronteira ou qualquer tipo de programa governamental, visto que além da lavagem de dinheiro, no decorrer dos anos, as ditas práticas foram tomando outras proporçóes, no sentido de náo lavar somente dinheiro em espécie, mas também bens e qualquer tipo de patrimônio que determinada pessoa possui, tornando ainda mais lícito o bem ilícito.

Nesse norte, procurou-se responder aos seguintes questionamentos: i) os programas de compliance adequam-se na seara empresarial, como forma de prevenir o cometimento de ilícitos financeiros, como o crime de lavagem de capitais.

Diante da estrutura apresentada, a conclusão, ou seja, a confirmação da hipótese é que os programas de compliance ou programas de integridade adequam-se na seara empresarial e, constituem uma ferramenta importante e frutífera para prevenir e corrigir o crime de lavagem de capitais, visto o poder de controle que os programas de compliance possuem na estrutura geral das empresas.

\section{REFERÊNCIAS}

ANTONIK, Luis Roberto. Compliance, ética, responsabilidade social e empresarial: uma visão prática. Rio de Janeiro: Alta Books, 2016.

BADARÓ, Gustavo Henrique; BOTTINI, Pierpaolo Cruz. Lavagem de dinheiro: aspectos penais e processuais penais. 3. ed. Sáo Paulo: Revista dos Tribunais, 2016.

BARROS, Marco Antônio de. Lavagem de capitais e obrigaçóes civis correlatas. São Paulo: Revista dos Tribunais, 2007. 
BRASIL. [Constituição (1988)]. Constituição da República Federativa do Brasil de 1988. Disponível em: <http://www.planalto.gov.br/ccivil_03/constituicao/ constituicaocompilado.htm>. Acesso em: 24 jul. 2020.

BRASIL. Lei 12.683, de 9 de julho de 2012. Crimes de Lavagem de dinheiro. Disponível em: <http://www.planalto.gov.br/ccivil_03/_Ato2011-2014/2012/Lei/L12683.htm>. Acesso em: 28 set. 2020.

BRASIL. Lei 12.846, de $1^{\circ}$ de agosto de 2013. Lei Anticorrupção. Disponível em: <http://www.planalto.gov.br/ccivil_03/_ato2011-2014/2013/lei/l12846.htm>. Acesso em: 26 set. 2020.

CUNHA, Rogério Sanches; SOUZA, Renee. Lei Anticorrupçáo empresarial. Salvador: Juspodivm, 2017.

DALLANORA, Anna Paula. Criminal compliance, no âmbito do Direito Penal Tributário. Rio de Janeiro: Lumen Juris, 2019.

JAPIASSÚ, Carlos Eduardo Adriano. A corrupção em uma perspectiva internacional. Revista Brasileira de Ciências Criminais. São Paulo: RT, 2007.

LOPES, Luciano Santos; CAMPOS, Renato Dilly. A omissão penalmente relevante e a função de garantidor do empresário. In: LOPES, Luciano Santos; MARTINS, Amanda Jales (orgs.). Direito penal econômico; tendências e perspectivas. Belo Horizonte: D’Plácido, 2017, p. 15 a 35.

MENDRONI, Marcelo Batlouni. Tópicos essenciais da lavagem de dinheiro. São Paulo: Revista dos Tribunais, v. 787, 2001.

MENDRONI, Marcelo Batlouni. Crime de lavagem de dinheiro. 4. ed. atual. e ampl. São Paulo: Atlas, 2018.

MORO, Sergio Fernando. Crime de lavagem de dinheiro. São Paulo: Saraiva, 2010.

NUCCI, Guilherme de Souza. Dicionário jurídico: Penal, Processo Penal e Execução Penal. São Paulo: Revista dos Tribunais, 2013.

RAMOS, André Luiz Santa Cruz. Direito Empresarial esquematizado. 7. ed. atual. e ampl. Rio de Janeiro: Método, 2017.

SANCTIS, Fausto Martins de. Crime organizado e lavagem de dinheiro. 1. ed. São Paulo: Saraiva, 2010.

SANTOS, José Anacleto Abduch; BERTONCINI, Mateus; COSTÓDIO FILHO, Ubirajara. Comentários à Lei 12.846/2013: Lei anticorrupçáo. 2. ed. rev., atual. e ampl. São Paulo: Revista dos Tribunais, 2015. 
SILVA, De Plácido e. Vocabulário jurídico. 30. ed. Rio de Janeiro: Forense, 2013.

SILVEIRA, Renato de Mello Jorge; DINIZ, Eduardo Saad. Compliance, Direito Penal e lei anticorrupçáo. São Paulo: Saraiva, 2015.

TEIXEIRA, Alexandre Alkmim. Compliance e informaçáo fiscal. Rio de Janeiro: Lumen Juris, 2019. 